\title{
A intenção de empreender e a formação dos futuros contadores
}

\section{Cristiane Krüger, Pedro Oliveira Homrich, Cláudia de Freitas Michelin, Jéssica da Silva Maciel}

\author{
Departamento de Ciencias Contables, Universidad Federal de Santa María - Brasil \\ Universidad Federal de Santa María - Brasil \\ Departamento de Ciencias Contables, Universidad Federal de Santa María - Brasil \\ Universidad Federal de Santa María - Brasil
}

Pesquisas afirmam que o mercado de trabalho na área de contabilidade exige profissionais com habilidades técnicas, relacionadas ao conhecimento operacional da profissão, e não técnicas, relacionadas às emoçôes e comportamentos. Esses termos advindos da literatura foram usados como forma de classificação das habilidades exigidas e instigadas. Perante sua relevância, o desenvolvimento de tais habilidades durante a formação tornou-se uma constante nos currículos. Nesse enfoque, classificou-se a intenção empreendedora como uma habilidade não técnica. Deste modo, objetivou-se analisar a intenção empreendedora de graduandos do curso de Ciências Contábeis da Universidade Federal de Santa Maria, relacionando-a com as Diretrizes Curriculares Nacionais para o curso. A pesquisa é classificada como quantitativa, descritiva e de levantamento. Os dados foram obtidos por meio da aplicaçáo de um questionário validado, contendo quatro dimensóes: atitudes pessoais, normas subjetivas, percepçáo de controle comportamental e intençáo empreendedora. Sendo que 202 acadêmicos de Ciências Contábeis participaram da pesquisa. Para os resultados verificou-se que o último semestre apresenta a média mais baixa para a dimensáo de intenção, o que sugere que ao final do curso os estudantes diminuem a intenção em empreender. Na correlação todas as dimensóes se associaram entre si, sendo a associação mais forte entre Intenção e atitudes pessoais. Na regressão todas as dimensões se mostraram significativas influenciadoras para a intençáo empreendedora. Conclui-se que as dimensôes estudadas contribuem para o desenvolvimento de competências e habilidades, mas nem todas estão previstas com clareza na legislaçáo em relação ao perfil do egresso. Como implicação, destaca-se a atenção para as habilidades não técnicas e sua importância para uma formação plena.

Palavras-chave: educação contábil, empreendedorismo, comportamento empreendedor, profissional contábil

\section{The intention to entrepreneur and the preparation of future accountants}

Research affirms that the job market in the accounting area requires professionals with technical skills, related to the operational knowledge of the profession, and non-technical ones, related to emotions and behaviors. These terms form the literature were used as a form of classification of required and instigated skills. Given its relevance, the development of such skills during training has become a constant in the curricula. In this approach, the entrepreneurial intention is classified as a non-technical skill. Thus, the objective was to analyze the entrepreneurial intention of undergraduates in the Accounting Course at the Federal University of Santa Maria, relating it to the National Curriculum Guidelines for the course. The research is classified as quantitative, descriptive, and survey. Data were obtained through the application of a validated questionnaire, containing four dimensions: Personal Attitudes, Subjective Norms, Perception of Behavioral 
Control, and Entrepreneurial Intention. A total of 202 accounting students participated in the research. For the results, it was found that the last semester has the lowest average for the dimension of intention, which suggests that at the end of the course, students decrease their intention to undertake. In the correlation, all dimensions were associated with each other, with the strongest association between Intention and Personal Attitudes. In the regression, all dimensions proved to be significant determinants of Entrepreneurial Intention. It is concluded that the studied dimensions contribute to the development of competencies and abilities, but not all are clearly foreseen in the legislation regarding the egress profile. As an implication, attention to non-technical skills and their importance for full training is highlighted.

Keywords: accounting education, entrepreneurship, entrepreneurial behavior, accounting professional

\section{La intención de emprender y la formación de futuros contadores}

Las investigaciones afirman que el mercado laboral en el área contable requiere de profesionales con competencias técnicas, relacionadas con el conocimiento operativo de la profesión; y no técnicas, relacionadas con las emociones y conductas. Estos términos de la literatura se utilizaron como una forma de clasificación de habilidades requeridas e instigadas. Dada su relevancia, el desarrollo de dichas habilidades durante la formación se ha convertido en una constante en los planes de estudio. Desde este enfoque, la intención empresarial se clasificó como una habilidad no técnica. Así, el objetivo de la investigación fue analizar la intención emprendedora de los egresados de la carrera de Contaduría de la Universidade Federal de Santa Maria, relacionándola con las directrices del plan de estudios nacional para el curso. La investigación fue en cuantitativa, descriptiva y de levantamiento de información. Se obtuvieron los datos mediante la aplicación de un cuestionario validado, que contiene cuatro dimensiones: actitudes personales, normas subjetivas, percepción de control conductual e intención emprendedora. La investigación recogió una muestra de 202 estudiantes de ciencias contables. A partir de los resultados, se encontró que el último semestre tiene el promedio más bajo para la dimensión de intención, lo que sugiere que, al final del curso, la intención de emprender disminuye en los estudiantes. En la correlación, todas las dimensiones se asociaron entre sí, y se encontró que la asociación más fuerte fue entre la intención y las actitudes personales. En la regresión, todas las dimensiones demostraron tener una influencia significativa en la intención empresarial. Así, se concluye que las dimensiones estudiadas contribuyen al desarrollo de competencias y habilidades, pero no todas están claramente previstas en la legislación en cuanto al perfil de salida. Como consecuencia, se destaca la atención a las habilidades no técnicas y su importancia para la formación completa.

Palabras clave: educación contable, emprendimiento, comportamiento emprendedor, contabilidad profesional.

\section{Introdução}

Estudiosos da área afirmam que a contabilidade sofreu nas últimas décadas rupturas e até mesmo mudança de paradigmas (Douglas \& Gammie, 2019). Pois o mercado, cada vez mais dinâmico, carece de profissionais com habilidades técnicas e não técnicas (Coady, Byrne, \& Casey, 2018). Esses autores dizem que essas habilidades não técnicas, identificadas como aquelas mais dirigidas às emoçóes e comportamentos, estão sendo questionadas e discutidas. Corroborando, Wakefield et al. (2019) afirmam que habilidades como liderança, comunicação, criatividade e habilidades multimídia são consistentes com as novas demandas da profissão. Dessa forma, é notório que as mesmas devam ser inseridas no currículo de cursos de contabilidade.

Partindo do princípio de que o curso de Ciências Contábeis é um curso de gestão que está classificado dentro da área de Administração, essa nova tendência vem a somar e contribuir para com a formação do perfil do egresso prevista nas Diretrizes Curriculares Nacionais 
(Resolução CNE/CES 10, 2004). Sendo atribuição das instituiçõos de ensino superior (em diante, IES) contribuir para a sociedade, uma das maneiras encontradas seria estimular açóes que representam importância para o progresso econômico e social da região na qual o curso está inserido.

Nesse sentido, o fomento ao empreendedorismo pode ser relevante quanto aos aspectos sociais, econômicos e comportamentais, o que pode acarretar na formaçáo de um campo de estudo intenso no que concerne aos aspectos individuais e coletivos, favorecendo a intenção dos indivíduos em tornarem-se empreendedores. Os traços de comportamento que sáo pertinentes aos empreendedores têm recebido atenção contínua de pesquisadores em instituiçóes que visam o crescimento pessoal e profissional do indivíduo, como as universidades por meio de seus diversos cursos de graduaçáo, entre outras atividades (Schaefer \& Minello, 2019).

Nas últimas décadas, o fomento ao empreendedorismo tem sido posto como prioridade nas pautas políticas, acadêmicas e econômicas no Brasil e em diversos países. Isso ocorre devido ao impacto comprovado que atividades empreendedoras exercem no desenvolvimento econômico e social de um país (Paul \& Shrivatava, 2016). O indivíduo empreendedor pode ser caracterizado como aquele que possui um diferencial em seu perfil que o torna singular, propiciando evoluçóes econômicas e conquista de bons resultados no que se refere à competitividade do mercado de trabalho (Rizzato \& Moran, 2013).

Deste modo, o incentivo à uma educação mais empreendedora viabiliza a possibilidade de o indivíduo desenvolver o seu comportamento quanto à formação de competências essenciais para empreender em diferentes áreas, como as industriais, comerciais ou de prestação de serviços (Schaefer \& Minello, 2019).
Em todas essas frentes o profissional da contabilidade pode atuar, por isso, o desenvolvimento das habilidades para empreender pode ser pertinente e relevante. A intenção empreendedora é parte constituinte desse comportamento, aspecto precedente da ação empreendedora, e indica o esforço que a pessoa fará para realizá-lo (Krüger \& Ramos, 2020).

Quanto maior a intenção de um indivíduo em realizar determinado comportamento, maior a probabilidade de que esse se efetive (Liñán \& Chen, 2009). Direcionando para os alunos de Ciências Contábeis, verifica-se que aqueles que participaram de disciplinas ou capacitaçóes relacionadas ao empreendedorismo durante a graduação desenvolveram uma intenção de empreender mais elevada frente aqueles que não haviam participado (Silva, Krüger, Minello e Ghilardi, 2019; Gieure, Benavides-Espinosa \& Roig-Dobón, 2020).

Dessa forma, considera-se que as IES são responsáveis pela promoção do potencial empreendedor quando engajadas na educação empreendedora. Delimitando-se a pesquisa para um curso de graduação em Ciências Contábeis, na Universidade Federal de Santa Maria (em diante, UFSM), questiona-se: qual a intençâo empreendedora dos futuros contadores e qual a relação desse comportamento com as Diretrizes Curriculares Nacionais para o curso?

Entendendo essa abordagem como pertinente no sentido de contribuir para a formaçáo do aluno, este estudo tem como objetivo geral analisar a intenção empreendedora de graduandos do curso de Ciências Contábeis da UFSM, relacionando-a com as Diretrizes Curriculares Nacionais para o curso. Para atingir tal objetivo foram elencados os seguintes objetivos específicos: i) verificar o perfil característico dos alunos do curso de Ciências Contábeis participantes da pesquisa; ii) descrever e mensurar a intenção empre- 
endedora existente nos respondentes; iii) mensurar estatisticamente a intenção empreendedora dos alunos participantes; e, iv) relacionar as competências e habilidades previstas na legislação vigente.

A análise da intenção empreendedora se justifica por ser considerada um dos pilares na possibilidade tangível de empreender (Lee, Wong, Foo, \& Leung, 2011) e se posiciona como gatilho de diversos outros fenômenos sociais (Jennings \& Brush, 2013). Martins, Santos e Silveira (2018) salientam a importância dos estudos de intenção empreendedora do ponto de vista prático e acadêmico, o que incentiva a realização desta pesquisa. Quanto à definição da população pesquisada, alunos de graduação, futuros contadores, tal escolha é justificada por corresponder à uma sugestão do estudo de Silva et al. (2019). Pico (2019) afirma que o contador é parte ativa nos processos organizacionais. Enquanto, Oliveira (2019) atenta para os diferentes papéis da contabilidade dentro do contexto organizacional, o que corrobora à realização desta pesquisa com esses estudantes, futuros profissionais da contabilidade.

Outro ponto motivacional diz respeito a lacuna de estudos na área de conhecimento relacionando aspectos comportamentais (intenção empreendedora) e a legislação curricular nacional para a formação do bacharel em Ciências Contábeis. Nesse sentido, o estudo se justifica por trazer uma contribuição teórica e prática, especialmente direcionadas para a formação dos contadores.

O presente artigo divide-se em cinco partes. A introdução contextualizou o tema da pesquisa, apresentando o problema e os objetivos. A seguir apresenta-se a revisão da literatura que norteou a análise e motivações da pesquisa. A terceira parte apresenta a metodologia aplicada na coleta de dados da pesquisa e posterior análise dos dados. A quarta seção apresenta e discute os resultados da análise de perfil, de estatística descri- tiva, correlação e regressóes. Por fim, a última seção do artigo pondera as considerações finais do estudo, com contribuiçôes, limitações e sugestôes para a temática.

\section{Revisão de literatura}

Nesta seção consta a base teórica e empírica utilizada para a estruturação do estudo, acerca dos seguintes temas: teoria do comportamento planejado (em diante, TCP), habilidades e competências previstas na legislação do curso de Ciências Contábeis e estudos assemelhados.

\subsection{Teoria do comportamento planejado}

A origem da TCP é atribuída ao trabalho de Ajzen (1991), intitulado "The theory of planned behavior". Neste estudo o autor argumenta que a TCP pode prever o comportamento quando comparado ao determinado pela confiabilidade comportamental (Ajzen, 1991). Conforme o autor, de acordo com esta teoria todo comportamento requer um certo planejamento (Ajzen, 1991). Tendo em vista esse modelo teórico, torna-se possível antecipar se determinado indivíduo vai criar um empreendimento futuramente, com base na análise de sua intenção. Para Fayolle e Liñán (2014), a intenção empreendedora é um tema vibrante no que se refere a estudos acerca do comportamento empreendedor.

Segundo Ajzen (1991), a TCP é do campo da psicologia social, correspondendo a uma extensão da teoria da ação racional. O que converge entre essas teorias é a intenção do indivíduo para adotar um determinado comportamento. Dessa forma, para Ajzen (1991), se uma pessoa tem os recursos necessários, oportunidades e intenção em executar determinado comportamento é provável que o realizará. Tal pressuposição foi validada por Kautonen, Van Gelderen e Fink (2015), que apontam que a intenção empreendedora é capaz de prever a ação de empreender. 
A TCP tem por objetivo explicitar, de modo geral, como se dá o comportamento em uma situação específica. Conforme essa teoria a intenção de realizar determinada ação e o comportamento são decorrências da combinação de três atitudes: i) atitude do indivíduo diante desse comportamento, (ii) da norma subjetiva que lhe é implícita e (iii) da percepção sobre o controle do comportamento em causa (Ajzen, 1991). Existe uma tendência quanto aos valores influenciarem de forma direta os antecedentes da intençáo bem como as atitudes, as normas sociais e também percepçôes de controle comportamental (Liñán \& Chen, 2009).

Com isso, infere-se a exequibilidade de empregar os fundamentos da TCP, no que concerne a intenção de empreender, para desvendar e predizer o comportamento empreendedor (Liñán \& Chen, 2009). $\mathrm{O}$ modelo de verificação da intenção empreendedora de Liñán e Chen (2009), elaborado com base na TCP de Ajzen (1991), é apresentado na figura 1.

\section{Figura 1. Intenção empreendedora com base na TCP}

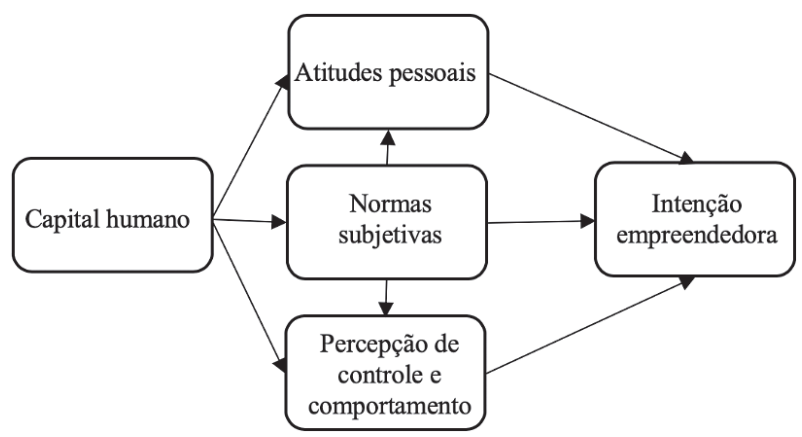

Fonte: adaptado de Liñán e Chen (2009).

A TCP tem sido avaliada em inúmeros estudos como modelo explicativo do comportamento humano, cujos resultados revelam capacidade explicativa satisfatória. Nesse sentido, se estabeleceu como uma das teorias que mais foram publicadas referente ao com-

portamento humano dentro do campo das ciências sociais (Almeida \& Sobral, 2005). De acordo com Ajzen (1991) "intençóes são utilizadas para capturar os fatores motivacionais que influenciam o comportamento e são indicadores de quanto às pessoas estáo dispostas a tentar ou a se esforçar para executar o comportamento" (p. 181).

Para as dimensóes que compóem o modelo de intençâo empreendedora de Liñán e Chen (2009), atitude pessoal diz respeito ao julgamento positivo ou negativo do indivíduo referente a realização de um determinado comportamento (Ajzen \& Fishbein, 1975). Correspondendo ao grau em que uma pessoa tem uma avaliação favorável ou desfavorável, ou avaliação do comportamento em questão (Ajzen, 1991). Sendo assim, se uma pessoa considera que um comportamento em específico condiz com suas crenças, esta pessoa possivelmente se posicionará de maneira favorável à execução deste comportamento.

Enquanto isso, as normas subjetivas dizem respeito à influência que o ambiente social tem em relação ao comportamento, demonstrando a pressão social para a adoção de um determinado comportamento. Liñán e Chen (2009) salientam que as normas subjetivas podem ter efeito sobre atitudes pessoais e percepção de controle comportamental. Para os autores, do ponto de vista do capital social, os valores transmitidos pelas "pessoas de referência", como os pais, causariam percepçôes mais favoráveis em relação às atitudes pessoais e ao controle comportamental percebido.

A percepção de controle comportamental, por conseguinte, de acordo com Liñán e Chen (2009), é diretamente proporcional ao quanto o indivíduo acredita poder executar determinado comportamento, "reflete a experiência passada, bem como impedimentos e obstáculos antecipados" (Ajzen, 1991, p. 189). Dessa 
forma, a percepção de controle comportamental retrata o entendimento do indivíduo acerca do nível de dificuldade percebido para a realização de um comportamento. Ajzen (1991) descreve que o comportamento das pessoas é fortemente influenciado por sua confiança em sua capacidade de executá-lo (ou seja, por controle comportamental percebido). As crenças de autoeficácia podem influenciar a escolha de atividades, a preparação para uma atividade, o esforço despendido durante o desempenho, bem como os padróes de pensamento e reaçóes emocionais (Ajzen, 1991).

$\mathrm{E}$ as intençôes são critérios que refletem o quão forte é a vontade de tentar, e a quantidade de esforço que o indivíduo está disposto a executar para manifestar um comportamento; enquanto o comportamento refere-se a maneira de agir do indivíduo (Ajzen, 1991). Para Thompson (2009), a intenção pode ser vista como uma deliberaçáo consciente e projetada, a qual impulsiona as ações necessárias para empreender, como iniciar um negócio. Sendo assim, conforme Liñán e Chen (2009), a intenção empreendedora individual é elemento crucial no que diz respeito ao estudo sobre a criação de novos empreendimentos. Como regra geral, quanto mais forte a intençáo de se envolver em um comportamento, mais provável deve ser seu desempenho (Ajzen, 1991). A seguir a legislaçáo pertinente à área do curso pesquisado é detalhada.

\subsection{Legislação vigente para o curso de Ciências Contábeis}

Com base na legislação vigente para o curso de Ciências Contábeis (Resolução CNE/CES 10, 2004), é esperado que o futuro contabilista seja capacitado, em seu artigo $3^{\circ}$, a:

I. compreender as questôes científicas, técnicas, sociais, econômicas e financeiras, em âmbito nacional e internacional e nos diferentes modelos de organização;
II. apresentar pleno domínio das responsabilidades funcionais envolvendo apuraçóes, auditorias, perícias, arbitragens, noçōes de atividades atuariais e de quantificações de informaçôes financeiras, patrimoniais e governamentais, com a plena utilização de inovaçóes tecnológicas;

III. revelar capacidade crítico-analítica de avaliação, quanto às implicaçóes organizacionais com o advento da tecnologia da informação" (Resolução CNE/CES 10, 2004).

Também a resolução diz em seu artigo $4^{\circ}$ que o curso deve possibilitar formação profissional, que revele, pelo menos, as seguintes competências e habilidades:

I. utilizar adequadamente a terminologia e a linguagem das Ciências Contábeis e Atuariais;

II. demonstrar visão sistêmica e interdisciplinar da atividade contábil;

III. elaborar pareceres e relatórios que contribuam para o desempenho eficiente e eficaz de seus usuários, quaisquer que sejam os modelos organizacionais;

IV. aplicar adequadamente a legislação inerente às funçôes contábeis;

V. desenvolver, com motivação e através de permanente articulação, a liderança entre equipes multidisciplinares para a captação de insumos necessários aos controles técnicos, à geração e disseminação de informaçôes contábeis, com reconhecido nível de precisão;

VI. exercer suas responsabilidades com o expressivo domínio das funções contábeis, incluindo noções de atividades atuariais e de quantificações de informaçôes financeiras, patrimoniais e governamentais, que viabilizem aos agentes econômicos 
e aos administradores de qualquer segmento produtivo ou institucional o pleno cumprimento de seus encargos quanto ao gerenciamento, aos controles e à prestação de contas de sua gestão perante à sociedade, gerando também informações para a tomada de decisão, organização de atitudes e construção de valores orientados para a cidadania;

VII. desenvolver, analisar e implantar sistemas de informação contábil e de controle gerencial, revelando capacidade crítico analítica para avaliar as implicaçôes organizacionais com a tecnologia da informação;

VIII. exercer com ética e proficiência as atribuiçóes e prerrogativas que lhe são prescritas através da legislação específica, revelando domínios adequados aos diferentes modelos organizacionais (Resolução CNE/CES 10, 2004).

Conforme legislação vigente, os cursos de contabilidade devem oferecer aos estudantes conteúdos de formação básica, de formação profissional e de formação teórico-prática, esses três pilares contemplarâo o perfil do egresso definido. Finalizando a revisão da literatura, os estudos assemelhados elencados para essa pesquisa são detalhados.

\subsection{Estudos assemelhados}

Nesta subseção são apresentados estudos semelhantes à pesquisa aqui realizada, no intuito de servir de base para as posteriores análises e discussóes. Cavalheiro, Krüger, Zonatto, Kaczam e Silva (2020) analisaram a intenção empreendedora dos estudantes de Ciências Contábeis, relacionando tal construto com motivação para aprender. Os autores constataram que os alunos que estão trabalhando na área contábil têm maior intenção em empreender diante dos que não estão, entretanto, sentem-se menos motivados a aprender.

Além disso, as análises revelaram relação entre normas subjetivas, intenção empreendedora e a variável sexo, como sendo explicativas para motivação para aprender (Cavalheiro et al., 2020).

O estudo de Silva et al. (2019) sobre intenção empreendedora em alunos de Ciências Contábeis, resultou em baixa intenção de empreender dos pesquisados, destacando que essa intenção reduz no decorrer do curso. Os autores identificaram que os alunos que participaram de disciplinas relacionadas ao empreendedorismo, os que estavam trabalhando e os que estavam cursando o curso no período noturno apresentaram uma intenção em empreender mais elevada em relação aos demais.

Souza, Silveira e Nascimento (2018) realizaram um estudo em duas universidades do estado do Mato Grosso do Sul, e tiveram como objetivo mensurar a intenção empreendedora de acadêmicos de Administração e Engenharia da Produção. Para realização do estudo foi aplicado o questionário de intenção empreendedora (em diante, QIE) em um total de 505 estudantes. A análise considerou modelagem de equaçóes estruturais. Os resultados validaram que a percepção de controle comportamental influencia a atitude pessoal, e que a atitude pessoal media a relação entre percepção de controle e intenção, e para a relação normas subjetivas e intenção. Essa relação entre percepção de controle e intenção e de normas subjetivas e intenção sofre influência de atitude pessoal.

Ainda, Birchler e Teixeira (2018) analisaram os fatores intrínsecos e extrínsecos que exercem influência sobre a intenção empreendedora de estudantes de vários cursos existentes no Instituto Federal do Espírito Santo (IFES), entre ensino técnico e cursos de graduaçấo. O estudo empírico abrangeu 1.267 respondentes, a metodologia utilizada foi quantitativa e descritiva, e o instrumento utilizado foi o QIE de Liñán e Chen 
(2009). Os autores efetuaram uma regressão linear múltipla com a intenção empreendedora como variável dependente e como variáveis independentes foram utilizadas as outras três dimensôes do questionário e fatores socioeconômicos dos participantes. Os resultados apontaram apenas fatores intrínsecos causando impacto na intenção empreendedora, representados pelas dimensóes de atitudes pessoais e percepção e controle de comportamento.

Loiola, Gondim, Pereira e Ferreira (2016) estudaram a intenção empreendedora de 2.999 estudantes de vários cursos de uma universidade pública no Brasil. Os autores objetivaram analisar o impacto das variáveis de percepção dentro do ambiente universitário e de variáveis motivacionais e atitudinais na intenção empreendedora dos jovens universitários. Também foi realizado um teste para avaliar a influência indireta da atitude positiva relacionada ao empreendedorismo nessas relaçóes. Os resultados apontaram que a motivação para o poder, sucedida pela aprendizagem empreendedora e uma menor percepção de risco são melhores preditores da intenção empreendedora. Além disso, a atitude positiva em relação ao empreendedorismo é mediadora dos efeitos das relaçóes entre motivos de poder, aprendizagem empreendedora e percepção de risco na intenção empreendedora.

Rocha e Freitas (2014) avaliaram o ensino de empreendedorismo entre estudantes universitários por meio do perfil empreendedor. $\mathrm{O}$ estudo teve por objetivo investigar, com o suporte de técnicas multivariadas, um instrumento que tem a função de medir a aprendizagem do ensino de Empreendedorismo, dessa forma verificou-se a mudança do perfil empreendedor. Evidenciou-se nos resultados que os estudantes participantes de atividades educacionais de formação em empreendedorismo demonstraram alteraçóes expressivas no perfil empreendedor.
Diante dos estudos assemelhados apresentados, percebe-se a carência de estudos que atentem para a formação do bacharel em Ciências Contábeis. Está lacuna motiva a realização do presente estudo. Isto posto, a seguir os procedimentos metodológicos são apresentados.

\section{Procedimentos metodológicos}

A presente pesquisa é classificada como quantitativa no que se refere à abordagem do problema, descritiva quanto aos objetivos e de levantamento quanto aos procedimentos utilizados (Vergara, 2016). A utilização de métodos quantitativos objetiva a descrição e/ou comparação de características sociais, instituiçóes ou determinados contextos, estabelecendo assim relaçóes causais (Ramos, 2013). Visto que pesquisa de levantamento utiliza amostras populacionais, mensurar as atitudes, opinióes e motivaçóes desse determinado grupo delimitado pela amostra é importante.

A população é composta por alunos do curso de Ciências Contábeis, dos turnos diurno e noturno, de uma universidade federal estabelecida no estado do RS (UFSM). O curso apresentava 392 alunos matriculados regularmente em março de 2018, sendo 187 do turno diurno e 205 do noturno. A amostra foi escolhida por conveniência pelos autores, tendo em vista acessibilidade para a coleta dos dados, que foi presencial.

Para o cálculo do tamanho mínimo da amostra optou-se pela fórmula constante na Equação 1, que segundo Fonseca e Martins (2011) é utilizada para estimar a amostra mínima de uma população finita. Com um nível de confiança considerado de $95 \%$ e um erro padrão de $5 \%$, estimou-se uma amostra mínima de 195 respondentes para a população de estudantes do curso. 


$$
\mathrm{n}=\frac{\mathrm{Z}_{\alpha / 2}^{2}{ }^{. \mathrm{p} . \mathrm{q} \cdot} \mathrm{N}}{\mathrm{e}^{2}(\mathrm{~N}-1)+\mathrm{Z}_{\alpha / 2}^{2}{ }^{. p . q}}
$$

Em que:

e - erro amostral;

$\mathrm{N}$ - tamanho populacional;

n - amostra mínima

$\alpha=0,05-$ Nível de Significância

$\mathrm{p}=0,5$ e $\mathrm{q}=0,5$;

$\mathrm{Z}_{\alpha / 2}^{2}=1,96$ para um nível de confiança de $95 \%$.

Para alcançar a amostra necessária, o passo seguinte foi realizar o levantamento dos horários e salas de aula das disciplinas do curso de Ciências Contábeis, tanto diurnas quanto noturnas. Os dados foram obtidos com a utilização do QIE de Liñán e Chen (2009), já validado no Brasil por Hecke (2011) em Curitiba - PR e Souza (2015) em Mato Grosso do Sul.

Hecke (2011) utilizou como método uma pesquisa descritiva do tipo survey, com questionário estruturado e uma amostra não probabilística, afirmando também que o questionário foi validado em uma pesquisa cross cultural. Souza (2015), por sua vez, utilizou o modelo de equaçóes estruturais, afirmando que este delineamento metodológico possibilitou a validação do modelo. Souza (2015) aponta que os principais resultados de seu estudo indicam que o questionário foi validado em um contexto regional, surgindo inclusive como sugestão de trabalhos futuros a aplicação do modelo e escala em outras universidades federais de outras regióes brasileiras. Deste modo, as dimensóes e respectivas variáveis do QIE são demonstradas na tabela 1 .

Com as informaçóes do QIE (tabela 1), almeja-se testar o modelo de intenção empreendedora (Liñán \& Chen, 2009). Conforme demonstrado na tabela 2, o instrumento é composto por quatro blocos referentes às dimensóes do QIE, com vinte assertivas no total. As dimensóes são: atitudes pessoais (cinco assertivas), normas subjetivas (três assertivas), percepção de controle comportamental (seis assertivas) e intenção empreendedora (seis assertivas).

\section{Tabela 1. Dimensóes e variáveis pesquiisadas}

\begin{tabular}{|ll|}
\hline \multicolumn{2}{|c|}{ Atitudes pessoais } \\
\hline 1. & $\begin{array}{l}\text { Ser um empreendedor traz mais vantagens do que desvan- } \\
\text { tagens para mim. }\end{array}$ \\
\hline 2. & A carreira de empresário é atraente para mim. \\
\hline 3. & $\begin{array}{l}\text { Se eu tivesse oportunidade e recursos, gostaria de criar } \\
\text { uma empresa. }\end{array}$ \\
\hline 4. & Ser um empreendedor me traria grande satisfação. \\
\hline 5. & Entre as várias opçóes, eu prefiro ser um empresário. \\
\hline
\end{tabular}

Normas subjetivas: se você decidisse empreender, que pessoas próximas a você iriam aprovar essa decisão?
6. Os seus parentes.
7. Os seus amigos.
8. Os seus colegas.

Percepçáo de controle comportamental: até que ponto você concorda com a seguinte declaraçáo a respeito de sua capacidade empreendedora?

9. Iniciar uma empresa e mantê-la funcionando seria fácil para mim.

10. Estou preparado para iniciar um negócio viável.

11. Eu posso controlar o processo de criação de uma nova empresa.

12. Eu conheço os detalhes práticos necessários para criar uma empresa.

13. Eu sei como desenvolver um projeto empresarial.

14. Se eu tentasse criar uma empresa, teria alta probabilidade de sucesso.

\section{Intenção empreendedora}

15. Eu estou disposto a fazer o que for preciso para ser um empresário.

16. Meu objetivo profissional é tornar-me um empresário.

17. Farei todos os esforços para criar e manter a minha própria empresa.

18. Eu estou decidido a criar uma empresa no futuro.

19. Tenho pensado muito seriamente em criar uma empresa.

20. Tenho a firme intenção de criar uma empresa dentro de pouco tempo.

Fonte: adaptado de Linān e Chen (2009). 
Tabela 2. Dimensóes e respectivas assertivas

\begin{tabular}{|c|c|}
\hline DIMENSÃO & ASSERTIVAS \\
\hline Atitudes pessoais & $\mathrm{Q} 1+\mathrm{Q} 2+\mathrm{Q} 3+\mathrm{Q} 4+\mathrm{Q} 5$ \\
\hline Normas subjetivas & $\mathrm{Q} 6+\mathrm{Q} 7+\mathrm{Q} 8$ \\
\hline $\begin{array}{l}\text { Percepção de controle } \\
\text { comportamental }\end{array}$ & $\mathrm{Q} 9+\mathrm{Q} 10+\mathrm{Q} 11+\mathrm{Q} 12+\mathrm{Q} 13+\mathrm{Q} 14$ \\
\hline Intenção empreendedora & $\mathrm{Q} 15+\mathrm{Q} 16+\mathrm{Q} 17+\mathrm{Q} 18+\mathrm{Q} 19+\mathrm{Q} 20$ \\
\hline
\end{tabular}

Fonte: adaptado de Linān e Chen (2009).

Ajzen (1991) define "atitude pessoal" como referente à avaliação do indivíduo frente a um determinado comportamento, avaliação essa que pode ser favorável ou não (tabela 1). O construto de normas subjetivas diz respeito à influência do ambiente social (pessoas próximas, como familiares e amigos) no comportamento, representando a pressão social para determinada maneira de se comportar (Hecke, 2011). A percepção de controle comportamental trata da percepçáo do indivíduo acerca da dificuldade para executar tal comportamento, de acordo com os recursos disponíveis e se o indivíduo é competente o suficiente para fazê-lo, sendo assim proporcional à crença individual de que tal comportamento é factível (Almeida, 2013). A intenção representa a intensidade da vontade de tentar, quanto esforço o indivíduo está propenso a executar para manifestar um certo comportamento (Ajzen, 1991).

Cada questão do instrumento é respondida de acordo com uma escala tipo Likert de 5 pontos, correspondendo a seguinte gradaçáo: 1 = Discordo totalmente, 2 = Discordo parcialmente, 3 = Não concordo nem discordo, 4 = Concordo parcialmente e 5 = Concordo totalmente. Previamente ao QIE, também constavam perguntas complementares acerca do perfil do respondente, referentes ao sexo, idade, estado civil, turno do curso, semestre do curso, se trabalha e se já foi aluno em alguma disciplina referente a empreendedorismo.
Todas as respostas foram anônimas, individuais e voluntárias.

A coleta de dados foi efetuada presencialmente durante as aulas do curso, com consentimento dos professores, exceto para alunos do décimo semestre, pois não possuem aula presencial encontrando-se matriculados apenas na disciplina de trabalho de conclusão de curso (TCC). Para eles foi disponibilizado um questionário em formato online, enviado por e-mail pela coordenação do curso. Participaram 202 respondentes durante o mês de abril de 2018, superando assim a amostra mínima estipulada.

Os dados obtidos no modelo proposto por Liñán e Chen (2009) foram codificados, tabulados e revisados em planilha eletrônica. O tratamento estatístico foi baseado em Hair Jr. et al. (2009), compreendendo estatística descritiva, com verificação de medidas de tendência central, medidas de dispersáo, teste Shapiro-Wilk de normalidade dos dados, do alfa de Cronbach e correlação de Pearson, e foi realizado na versão 20 do software IBM SPSS Statistics. A execução e análise de regressóes foi efetuada no software STATA 14. A análise e discussão dos resultados encontrados é apresentada na seção a seguir.

\section{Análise e discussão dos resultados}

A presente seção mostra os resultados obtidos com as análises dos dados coletados, discutindo e comparando com observaçóes de outros autores relacionados à temática. Inicialmente, apresenta-se um panorama da amostra e suas características gerais, prosseguindo após para a análise estatística e regressiva dos dados.

\subsection{Características gerais da amostra}

$\mathrm{O}$ instrumento de pesquisa apresentava como questóes iniciais para caracterizar o perfil da amostra: sexo, 
idade, estado civil, turno do curso, se trabalha e se já cursou alguma disciplina relacionada a empreendedorismo. Dos 202 respondentes, 94 são do sexo masculino (46,5\% da amostra) e 108 são do sexo feminino (53,5\% da amostra). Quanto ao semestre dos alunos, as frequências de resposta constam na figura 2 .

Figura 2. Semestre dos alunos respondentes

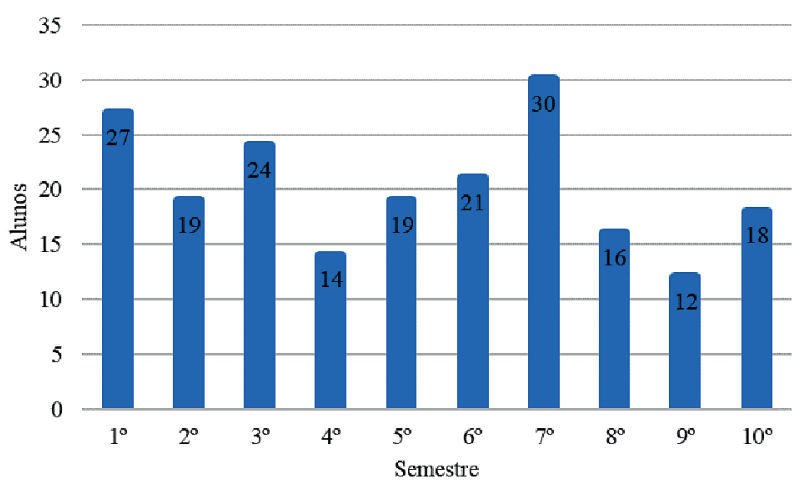

Dois alunos não informaram o semestre (figura 2). Dos 200 alunos que responderam, a maior parte estava no sétimo semestre $(14,9 \%)$ e no primeiro semestre $(13,4 \%)$. Aproximadamente $51 \%$ da amostra está nos primeiros cinco semestres do curso de Ciências Contábeis e o restante (49\%) nos cinco semestres seguintes, paridade também demonstrada pela média dos semestres, de valor 5,15.

Os respondentes, em sua maioria, estudam no turno noturno 114 alunos (56,4\% da amostra), e 133 alunos $(65,8 \%$ da amostra) trabalham. Cabe destacar que, conforme Krüger e Ramos (2020), alunos que estão trabalhando na área contábil têm maior intenção em empreender diante dos que não estão. Ainda, dos 202 respondentes, 144 alunos, ou seja, 71,3\% da amostra, responderam que ainda não cursaram disciplinas relacionadas a empreendedorismo. Salienta-se que alunos que vivenciaram o empreendedorismo em sua formação acadêmica demonstraram alterações positivas no perfil empreendedor (Rocha \& Freitas, 2014). A tabela 3 apresenta a faixa etária da amostra pesquisada.

Tabela 3. Faixa etária da amostra

\begin{tabular}{|l|c|c|}
\hline \multicolumn{1}{|c|}{ Idade } & Participantes & Porcentagem \\
\hline Menor de 18 anos & 10 & $4,95 \%$ \\
18 até 23 anos & 130 & $64,36 \%$ \\
24 até 29 anos & 36 & $17,82 \%$ \\
Acima de 29 anos & 26 & $12,87 \%$ \\
\hline Total & $\mathbf{2 0 2}$ & $\mathbf{1 0 0} \%$ \\
\hline
\end{tabular}

Acerca da faixa etária da amostra, 140 respondentes possuem até 23 anos, ou seja, 69,31\% da amostra (tabela 3). O estado civil da maioria dos respondentes é solteiro, conforme resposta de 183 alunos (90,6\% da amostra). Percebe-se assim, tendo em vista os resultados predominantes na parte sociodemográfica do questionário, que os participantes da pesquisa se caracterizam como jovens solteiros, predominantemente inseridos no mercado de trabalho e que em sua maioria náo cursaram disciplinas relacionadas ao empreendedorismo.

\subsection{Estatística descritiva}

Após caracterização da amostra efetuou-se a análise estatística descritiva dos itens do QIE e de suas respectivas dimensóes. Foi calculado o alfa de Cronbach para medir a confiabilidade entre os indicadores de construto. Os valores do alfa variam de 0 a 1 , sendo que quanto mais próximo de um, maior a confiabilidade entre os indicadores componentes do instrumento (Hair Jr. et al., 2009).

O alfa de Cronbach obtido no estudo foi de $\alpha=0,61$ para o construto de atitude pessoal, $\alpha=0,78$ para normas subjetivas, $\alpha=0,77$ para percepçáo de controle comportamental, $\alpha=0,58$ para intenção empreendedora, 
e $\alpha=0,75$ para o instrumento como um todo, estando no espectro de consistência "substancial" para o alfa, entre 0,61 a 0,80 (Landis \& Koch, 1977). Na tabela 4 constam as estatísticas de tendência central e dispersão para cada dimensão do questionário aplicado.

\section{Tabela 4. Medidas de tendência central e dispersáo}

\begin{tabular}{|l|c|c|c|c|}
\hline \multicolumn{1}{|c|}{ Dimensóes } & Mínimo & Máximo & Média & $\begin{array}{c}\text { Desvio- } \\
\text { Padrão }\end{array}$ \\
\hline Atitude pessoal & 5 & 25 & 17,945 & 5,006 \\
Normas subjetivas & 3 & 15 & 11,436 & 2,631 \\
$\begin{array}{l}\text { Percepção de controle } \\
\text { comportamental }\end{array}$ & 7 & 30 & 17,188 & 4,956 \\
\begin{tabular}{l} 
Intenção empreendedora \\
\hline
\end{tabular} & 6 & 30 & 16,639 & 6,838 \\
\hline
\end{tabular}

Tendo em vista a quantidade de questóes que compóe cada bloco, os valores máximos e mínimos possuem diferenças entre cada dimensão. Nesse sentido, embora a média de atitude pessoal tenha o maior valor absoluto entre as quatro dimensões, é necessário observar em relação ao valor máximo possível para a referida dimensão. A figura 3 demonstra a comparação das médias observadas e o valor máximo da dimensão:

\section{Figura 3. Média observada das dimensóes do QIE e valor máximo}

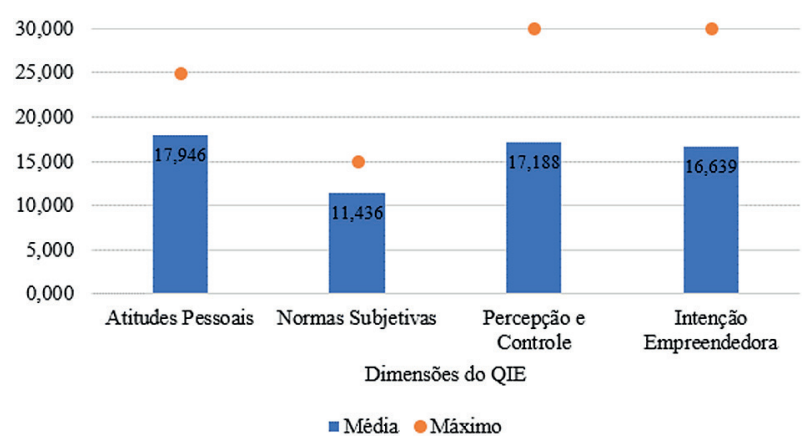

A partir da figura 3 observa-se que ainda que a dimensão de atitudes pessoais apresente a maior média absoluta, quando comparada proporcionalmente com o valor máximo possível, a dimensão com maior média relativa é normas subjetivas, com média igual a $76,24 \%$ do valor máximo. Em seguida, tem-se atitudes pessoais com $71,78 \%$ do valor máximo, percepção de controle comportamental com $57,29 \%$ e intenção empreendedora com $55,46 \%$ do valor máximo para a respectiva dimensão.

Ao analisar a média de intenção empreendedora por idade e por gênero dos respondentes, verifica-se que o gênero masculino possui maior média de intenção empreendedora, que foi de 18,09, enquanto a do gênero feminino foi de 15,38. Quanto à idade dos respondentes, a média de intençáo empreendedora da faixa menor de 18 até 23 anos foi 16,97, enquanto a média dos com idade de 24 anos ou mais foi de 15,89. Verifica-se assim uma tendência de maior intenção empreendedora por parte dos jovens e do gênero masculino.

A dimensão de normas subjetivas representa a influência do ambiente social no comportamento do respondente, consistindo no primeiro filtro acerca dos incentivos externos ao contato com o empreendedorismo (Liñán \& Chen, 2009), relacionando-se com a noção percebida pelo aluno se suas "pessoas-referência” aprovariam a decisão de tornar-se um empreendedor (Souza et al., 2018). Sendo a maior média relativa verificada, percebe-se que os alunos consideram importante a opinião externa na hora de avaliar o engajamento em atividades empreendedoras. Essa dimensão pode ser bem explorada na medida em que o curso proporciona atividades complementares, estágio supervisionado, atividades de extensão, previstas na formação teórico-prática (Resolução CNE/CES 10, 2004), no sentido de estimular o aluno a buscar referências externas para sua formação. $\mathrm{Na}$ figura 4 consta a comparação das médias de cada dimensão entre os semestres do curso, considerando os cinco primeiros semestres (metade do curso) e os semestres finais. 
Figura 4. Comparativo entre os semestres do currso

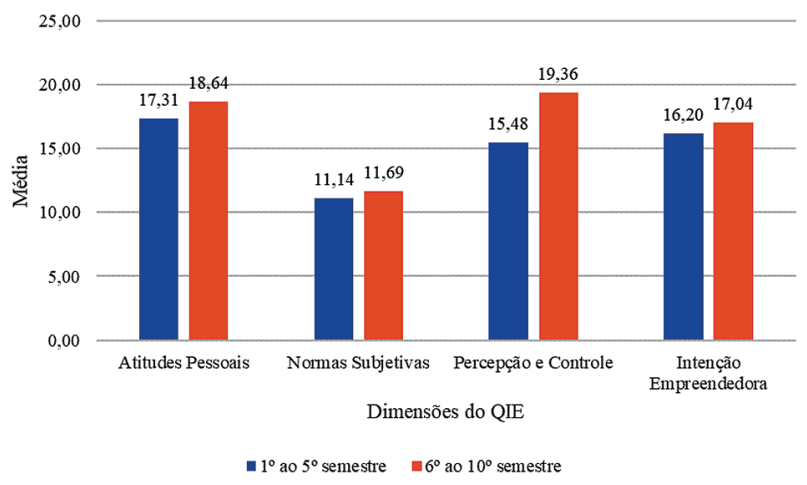

A figura 4 demonstra que a média de todas as dimensóes é mais elevada do $6^{\circ}$ ao $10^{\circ}$ semestre do curso de Ciências Contábeis, sendo tal aumento ainda mais expressivo em percepção de controle comportamental (média 25,06\% maior) e atitudes pessoais (média 7,68\% maior). $\mathrm{O}$ teste t por pares relacionando as dimensóes com o semestre dos respondentes foi significativo, demonstrando que a diferença é estatisticamente significante.

Liñán e Chen (2009) ponderam que a dimensão de percepção de controle comportamental tem relação direta com a convicção do indivíduo na possibilidade de executar um comportamento específico, indicando que, com base na diferença de médias apresentadas, indivíduos do quinto ao décimo semestre possuem pontuações maiores nessa dimensão do QIE, reforçando tal convicção. Souza et al. (2018) também validaram a dimensão de percepção de controle comportamental como determinante para a pretensão em empreender, demonstrando que o aluno acredita no seu conhecimento e potencial, e que tem condiçôes favoráveis para isso. Visto que apresenta elevada variância, a dimensão de intenção empreendedora demonstra que houve a maior disparidade de respostas dentro da amostra. Nesse sentido, a figura 5 relaciona a média dessa dimensão para cada semestre dos alunos pesquisados.
Figura 5. Média de intençáo empreendedora por semestre

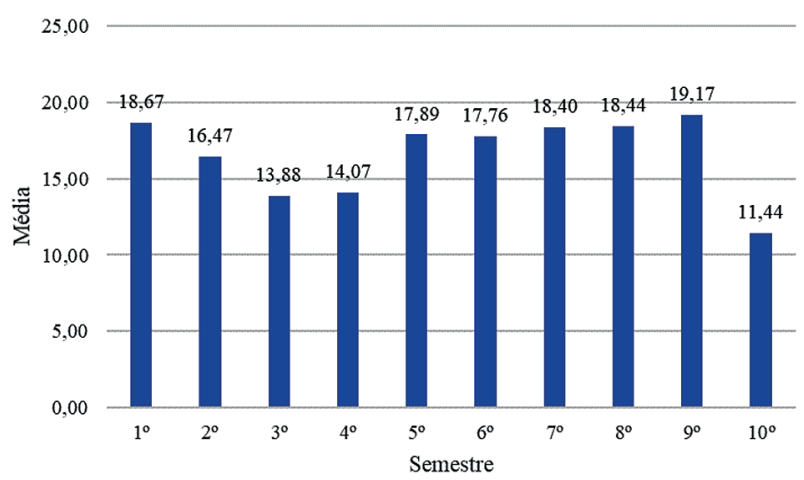

Relacionando a média de intenção empreendedora com o semestre do aluno no curso, percebe-se que a média é menor no último semestre do curso, se mantendo relativamente elevada do $6^{\circ}$ ao $9^{\circ}$ semestre e no primeiro. Embora acentuada nos semestres próximos ao fim do curso, a média da intenção empreendedora reduz no último semestre, quando o aluno está próximo de concluir a graduação. Esse resultado é suportado por Silva et al. (2019), que também concluíram que a intenção reduz no final do curso.

Ajzen (1991) definiu "intençãa" como esforço exercido pelo indivíduo, para efetuar determinada atividade empreendedora, ou esforço que o indivíduo pretende exercer. Visto que é a dimensão com variância mais elevada, pode-se inferir que há disparidade na intenção dos alunos de Ciências Contábeis em criarem um negócio ou náo. Ao final do curso, quando se entende que o estudante está mais apto a empreender tendo em vista o arcabouço teórico e prático adquirido durante o curso de graduação, o formando de contábeis tem sua intenção de empreender diminuída. Esse resultado causa estranheza e oportuniza a realização de estudo futuro com maior aprofundamento qualitativo, especialmente com os alunos do último semestre. 
Esse dado de intenção de empreender diminuída, ao relacionar com as competências e habilidades do perfil do egresso, restritas ao conhecimento técnico dentro de organizações e demonstraçôes contábeis (Resolução CNE/CES 10, 2004, art. 4,), pode sugerir uma lacuna de outras habilidades exigidas pelo mercado na qual a própria legislação não prevê. Percebe-se que as habilidades técnicas são visíveis nos conteúdos de formação e que as habilidades não técnicas não estão explicitas, por isso a discussão pertinente de pesquisas atuais em relação a alteração e mudança nos currículos, uma vez que o mercado demanda um perfil profissional diferenciado.

Em seguida, ainda na análise descritiva, foram verificadas as associaçóes entre as dimensóes do QIE por meio da análise de correlação, que mensura o grau de relação linear entre duas variáveis. Para isso adotou-se o coeficiente de correlação de Pearson em que (r) varia de $-1 \mathrm{a}+1$, em que valores próximos $\mathrm{a}+1$ indicam pouca dispersão, uma correlação forte e positiva ou negativa, de acordo com o sinal, enquanto valores próximos a 0 indicam alta dispersão e pouca ou nenhuma relação entre as variáveis. Constam na tabela 4 os coeficientes apresentados para as dimensões pesquisadas.

Tabela 4. Correlaçáo entre as dimensóes da intençáo

\begin{tabular}{|c|c|c|c|c|}
\hline Dimensốes & $\begin{array}{c}\text { Ati- } \\
\text { tudes } \\
\text { pessoais }\end{array}$ & $\begin{array}{l}\text { Normas } \\
\text { subjeti- } \\
\text { vas }\end{array}$ & $\begin{array}{l}\text { Percepçáo } \\
\text { Compor- } \\
\text { tamental }\end{array}$ & $\begin{array}{c}\text { Intenção } \\
\text { empreen- } \\
\text { dedora }\end{array}$ \\
\hline Atitudes pessoais & 1 & & & \\
\hline Normas subjetivas & $0,426^{* *}$ & 1 & & \\
\hline $\begin{array}{l}\text { Percepção compor- } \\
\text { tamental }\end{array}$ & $0,385^{* *}$ & $0,141^{*}$ & 1 & \\
\hline $\begin{array}{l}\text { Intenção empreen- } \\
\text { dedora }\end{array}$ & $0,748^{* *}$ & $0,398^{* *}$ & $0,485^{* *}$ & 1 \\
\hline
\end{tabular}

**Correlação significativa ao nível 0,01 (bilateral).

${ }^{*}$ Correlação significativa ao nível 0,05 (bilateral).
Adotando a conversão de Dancey e Reidy (2013), que especifica correlação fraca para $r=0,10$ a 0,39 ; correlação moderada para $r=0,40$ a 0,69 e correlação forte para $r=0,70$ a 1,00 , verifica-se que a única correlação considerada forte é entre atitude pessoal e intenção empreendedora. A dimensão de percepção de controle comportamental apresentou correlação fraca com atitudes pessoais $(0,385)$ e normas subjetivas $(0,141)$, e correlação moderada com intenção empreendedora $(0,485)$.

A dimensão de normas subjetivas apresentou correlação moderada com atitudes pessoais $(0,426)$ e intenção empreendedora (aprox. 0,40). Todas as correlaçóes positivas e estatisticamente significativas demonstram a influência direta das dimensóes entre si, onde o incremento de uma delas conduz um aumento na percepção das outras dimensóes. Os resultados encontrados são similares aos encontrado por Souza et al. (2018), que encontraram relaçáo positiva e significante entre cada par de dimensões do QIE.

Após a verificação de relevância estatística entre as dimensóes, foi efetuada a análise regressiva dos construtos. Tendo em vista a normalidade das variáveis, conforme resultado significativo do teste Shapiro-Wilk, o uso de regressões e teste ANOVA é viável na presente pesquisa. Na tabela 5 apresentam-se os valores obtidos com a regressão estimada da intenção empreendedora como variável dependente.

Efetuando-se a regressão da intenção empreendedora em função das demais variáveis e de uma constante, obtêm-se que o $\mathrm{R}^{2}$, indicativo da porcentagem da variável dependente que é explicada pelas variáveis independentes, é de 61,3\% (tabela 5). O teste ANOVA foi significativo ao nível de 0,01 . Todos os coeficientes apresentaram significância em relação à intenção empreendedora como variável dependente. 
Tabela 5. Regressáo estimada da intençáo empreendedora

\begin{tabular}{|c|c|c|c|c|c|}
\hline $\mathbf{R}^{\mathbf{2}}$ & $\begin{array}{c}\text { Variável } \\
\text { dependente }\end{array}$ & $\begin{array}{c}\text { Variáveis inde- } \\
\text { pendentes }\end{array}$ & $\begin{array}{c}\text { Coefi- } \\
\text { ciente }\end{array}$ & $\begin{array}{c}\text { Desvio } \\
\text { Padrão }\end{array}$ & Sig. \\
\hline 0,613 & $\begin{array}{c}\text { Intenção } \\
\text { empreende- } \\
\text { dora }\end{array}$ & Constante & $-7,030$ & 1,631 & 0,000 \\
\cline { 3 - 6 } & $\begin{array}{c}\text { Atitudes pes- } \\
\text { soais }\end{array}$ & 0,835 & 0,072 & 0,000 \\
\cline { 3 - 6 } & $\begin{array}{c}\text { Normas subje- } \\
\text { tivas }\end{array}$ & 0,268 & 0,127 & 0,036 \\
\cline { 5 - 6 } & $\begin{array}{c}\text { Percepção de } \\
\text { controle com- } \\
\text { portamental }\end{array}$ & 0,326 & 0,066 & 0,000 \\
\hline
\end{tabular}

Os resultados da regressão estimada condizem com os achados de Birchler e Teixeira (2018), que identificaram fatores intrínsecos influenciado na intenção empreendedora, ou seja, as dimensóes de atitudes pessoais e percepção de controle comportamental, ambas positivas e significativas na regressão estimada de intenção empreendedora como variável dependente. Vale ressaltar que os autores incluíram em suas regressóes, além das dimensões do QIE, fatores socioeconômicos e relacionados ao perfil dos respondentes do questionário, mas ainda assim apenas os fatores intrínsecos mencionados demonstraram influência na intenção empreendedora.

Os resultados estatísticos desta pesquisa trazem a reflexão abordada no início, na inquietação de que formar contadores com habilidades técnicas é indispensável, mas que o olhar para as habilidades não técnicas se faz necessário, porque se o mercado está mudando e exigindo um profissional diferenciado, logo a legislação e os currículos também devem ser revistos, pensados, alterados e atualizados.

A não intenção empreendedora de alunos finais remete a uma lacuna na formação desses alunos, o que pode estar relacionado com o fato de os alunos pesquisados não terem cursado disciplinas referentes a empreende- dorismo. Pode-se atribuir ainda a redução na intençâo empreendedora dos alunos à medida que o curso avança em virtude da inserção no mercado de trabalho dos alunos nos semestres finais, o que causaria uma redução na vontade de empreender. Salienta-se que não está em análise nessa pesquisa que o curso em questão deva formar empreendedores, mas sim que, ao promover açóes que estimulem o empreendedorismo na área de contabilidade, o profissional formado atenda a outras habilidades além das já previstas.

As competências e habilidades previstas na legislação, a saber: "II - demonstrar visão sistêmica e interdisciplinar da atividade contábil" e "V - desenvolver, com motivação e através de permanente articulação, a liderança entre equipes multidisciplinares para a captação de insumos necessários aos controles técnicos, à geração e disseminação de informações contábeis, com reconhecido nível de precisáo" quando bem desenvolvidas remetem a açóes que podem desenvolver e estimular o empreender.

À medida que é exigido que os cursos contemplem, em seus projetos pedagógicos e em sua organização curricular, conteúdos que revelem conhecimento do cenário econômico e financeiro, nacional e internacional, de forma a proporcionar a harmonização das normas e padróes internacionais de contabilidade, em conformidade com a formação exigida pela Organização Mundial do Comércio e pelas peculiaridades das organizaçóes governamentais, observado o perfil definido para o formando e que atendam aos campos interligados de formação básica, profissional e teórico-prática (Resolução CNE/CES 10, 2004, art. 5), é esperado que o acadêmico tenha ao final dos anos de formação as habilidades exigidas.

As dimensôes estudadas, atitudes pessoais, normas subjetivas, percepção de controle comportamental, intenção

Contabilidad y Negocios (16) 32, 2021 / ISSN 1992-1896 
empreendedora podem ser caracterizadas, fundamentada na legislação vigente e nas referências apontadas nessa pesquisa, como habilidades não técnicas, consideradas na atualidade como importantes para a formação do acadêmico (Coady et al., 2018; Wakefield et al., 2019). Ao desenvolver tais habilidades, o curso atende também a um dos objetivos propostos para a universidade, que é o retorno para a sociedade, em benefício do desenvolvimento social e econômico. Esse retorno pode alterar os índices locais e favorecer o crescimento. Os cursos considerados de gestão são os mais propícios para atender a esse objetivo, logo o curso de Ciências Contábeis também teria esse propósito social.

\section{Conclusáo}

Diante de cenários de desemprego e desigualdade social, o empreendedorismo é uma opção para os brasileiros, consistindo em uma alternativa para a geração de trabalho e consequente formação de uma classe empreendedora (Barros, Fiúsa, \& Ipiranga, 2005). Nesse sentido, o presente estudo analisou a intenção empreendedora de graduandos do curso de Ciências Contábeis da UFSM relacionando com as Diretrizes Curriculares Nacionais para o curso (Resolução CNE/CES 10, 2004).

Os acadêmicos pesquisados são predominantemente jovens, solteiros, inseridos no mercado de trabalho e que não cursaram disciplinas relacionadas a empreendedorismo. A variância apresentada na dimensão de intenção empreendedora foi a mais elevada, indicando discrepância entre as respostas, sobretudo quando separadas por semestre, em que os respondentes do último semestre apresentaram a menor média de intenção empreendedora.

Todas as correlações verificadas entre as dimensões componentes do QIE foram positivas e significativas, sendo a mais expressiva entre intenção empreendedora e atitudes pessoais. Os resultados dessa pesquisa vão ao encontro dos trabalhos assemelhados analisados. Além disso, esse estudo preocupou-se em analisar a legislação vigente, uma vez que é notável a mudança no mercado de trabalho para o profissional contador e outras habilidades além das técnicas são exigidas.

Os alunos participantes da pesquisa possuem intenção empreendedora e nesse sentido pode-se afirmar que eles querem empreender, embora não em um número máximo absoluto. Esse dado pode ser relacionado com as ações desenvolvidas ao longo do curso, ações essas que podem envolver muitas habilidades técnicas como também podem não envolver habilidades não técnicas. Novos questionamentos são levantados sugerindo atualização na legislação e nos currículos dos cursos, o novo perfil do egresso para o futuro profissional deve ser pauta nos debates e na inserção nos projetos pedagógicos dos cursos de contabilidade.

Sabe-se o quão importante são as habilidades técnicas para o futuro profissional se destacar no mercado de trabalho, mas o olhar para as habilidades não técnicas se faz necessário e essa certeza foi uma das motivações dessa pesquisa, no sentido de trazer um questionamento crítico em relação ao perfil do egresso que se quer formar atualmente. Entre todos achados e a contextualização que norteou essa pesquisa, a indagação de que a plenitude de habilidades tanto técnicas quanto não técnicas favorece para a condução profissional, é uma implicação que merece destaque tanto entre pesquisadores quanto nos currículos apresentados pelas entidades de formação.

Os resultados encontrados contribuem para um panorama analítico da intenção empreendedora dos alunos dessa amostra, podendo propiciar alterações no curso em prol de uma educaçáo mais empreendedora e um engajamento dos agentes interessados na temática 
empreendedora. Compreender e verificar a percepção atual dos alunos possibilita abordagens para fomentar iniciativas nesse tema, refletir sobre as novas demandas de mercado e sobre o perfil do egresso que atenda à essa demanda. Habilidades técnicas são indispensáveis e habilidades não técnicas contribuem significativamente para a formação de um profissional preparado para o mundo dinâmico e sistêmico de atualidade.

Alguns limitantes do estudo consistem na falta de uma metodologia que viabilize verificar os condicionantes das dimensóes apresentadas, além de referir-se a uma pesquisa com corte transversal. Todos esses apontamentos ou questionamentos são propositivos para a inspiração de novas pesquisas sobre a temática. Além disso, seria relevante agregar outros aspectos comportamentais como liderança, engajamento e motivação, constructos também consolidados na literatura.

\section{Referências}

Ajzen, I. (1991). The theory of planned behavior. Organizational Behavior and Human Decision Processes, 50(2), 179-211. https://doi.org/10.1016/0749-5978 (91)90020-T

Ajzen, I., \& Fishbein, M. (1975). A bayesian analysis of attribution processes. Psychological Bulletin, 82(2), 261-277. https://doi.org/10.1037/h0076477

Almeida, F. J. R. de, \& Sobral, F. J. B. de A. (2005). Os condicionantes psicológicos e estruturais da informatizaçâo organizacional: Um estudo sobre empresas portuguesas utilizando o modelo de equaçóes estruturais. Recuperado de http://www.anpad.org.br/admin/pdf/ enanpad2005-adic-0519.pdf [Consulta:dez. 2020].

Almeida, G. O. (2013). Valores, atitudes e intenção empreendedora: Um estudo com universitário brasileiros $e$ cabo-verdianos (Tese de doutorado, Escola Brasileira de Administração Pública e de Empresas, Fundaçáo Getúlio Vargas. Rio de Janeiro, Brasil).
Barros, F. S. de O., Fiúsa, J. L. A., \& Ipiranga, A. S. R. (2005). O empreendedorismo como estratégia emergente de gestáo: Histórias de sucesso. Organizaçôes e Sociedade, 12(33), 109-28. https://doi.org/10.1590/ S1984-92302005000200006

Birchler, E. A., \& Teixeira, A. (2018). A intenção empreendedora de estudantes e os fatores que a influenciam. Revista de Negócios, 22(2), 7-22. https://doi. org/10.7867/1980-4431.2017v22n2p7-22

Conselho Nacional de Educaçấo Brasil. (2004, 16 de dezembro). Institui as Diretrizes Curriculares Nacionais para o Curso de Graduação em Ciências Contábeis, bacharelado, e dá outras providências [Resolução CNE/ CES No 10/2014].

Cavalheiro, G. M., Krüger, C., Zonatto, V. C. L., Kaczam, F., \& Silva, L. I. (2020, 25-27 de novembro). Intençáo empreendedora e motivaçáo para aprender em graduandos do curso de Ciências Contábeis da UFSM [Apresentaçáo da conferência]. XXIII SEMEAD Seminários em Administração, São Paulo, Brasil.

Coady, P., Byrne, S., \& Casey, J. (2018). Positioning of emotional intelligence skills within the overall skillset of practice-based accountants: Employer and graduate requirements. Accounting Education, 27(1), 94-120. https://doi.org/10.1080/09639284.2017.1384741

Dancey, C. P., \& Reidy, J. (2013). Estatística sem matemática para psicologia. Porto Alegre: Penso Editora.

Douglas, S., \& Gammie, E. (2019). An Investigation into the Development of Non-Technical Skills by Undergraduate Accounting Programmes. Accounting Education, 28(3), 304-32. https://doi.org/10.1080/096392 84.2019 .1605532

Fayolle, A., \& Liñán, F. (2014). The future of research on entrepreneurial intentions. Journal of Business Research, 67(5), 663-66. https://doi.org/10.1016/j. jbusres.2013.11.024

Fonseca, J. S. da, \& Martins, G. de A. (2011). Curso de estatística. São Paulo: Editora Atlas S.A.

Contabilidad y Negocios (16) 32, 2021 / ISSN 1992-1896 
Gieure, C., Benavides-Espinosa, M. del M., \& Roig-Dobón, S. (2020). The entrepreneurial process: The link between intentions and behavior. Journal of Business Research, 112. 541-548. https://doi.org/10.1016/j. jbusres.2019.11.088

Hair Jr., J. F., Black, W. C., Babin, B., Anderson, R. E., \& Tatham, R. L. (2009). Análise multivariada de dados. Porto Alegre: Bookman.

Hecke, A. P. (2011). Intençấo empreendedora dos alunos concluintes dos cursos de graduação em Administração e Ciências Contábeis das instituiçôes de ensino superior de Curitiba-PR. (Dissertação de mestrado, Ciências Sociais, Universidade Federal do Paraná. Curitiba, Brasil).

Kautonen, T., Van Gelderen, M., \& Fink, M. (2015). Robustness of the theory of planned behavior in predicting entrepreneurial intentions and actions. Entrepreneurship Theory and Practice, 39(3), 655-74. https://doi.org/10.1111/etap.12056

Krüger, C., \& Ramos, L. F. (2020). Comportamento empreendedor, a partir de características comportamentais e da intenção empreendedora. REGEPE - Revista de Empreendedorismo e Gestão de Pequenas Empresas, 9(4), 556-583. https://doi.org/10.14211/regepe.v9i4.1544

Jennings, J. E., \& Brush, C. G. (2013). Research on women entrepreneurs: challenges to (and from) the broader entrepreneurship literature? The Academy of Management Annals, 7(1), 663-715. https://doi.org/10.1080 /19416520.2013.782190

Landis, J. R., \& Koch, G. G. (1977). The measurement of observer agreement for categorical data. International Biometric Society, 33(1), 159-74. https://doi. org/10.2307/2529310

Lanero, A., Vázquez, J. L., Gutiérrez, P., \& García, M. P. (2011). The impact of entrepreneurship education in european universities: An intention-based approach analyzed in the spanish area. International Review on Public and Nonprofit Marketing, 8(2),111-30. https:// doi.org/10.1007/s12208-011-0067-8
Lee, L., Wong, P. K., Foo, M. D., \& Leung, A. (2011). Entrepreneurial intentions: the influence of organizational and individual factors. Journal of Business Venturing, 26(1), 124-136. https://doi.org/10.1016/j. jbusvent.2009.04.003

Lima, E., Nassif, V. M. J., Lopes, R. M. A., \& Silva, D. da. (2014). Educaçẫo superior em empreendedorismo e intençôes empreendedoras dos estudantes - Relatório do Estudo GUESSS Brasil 2013-2014 (Caderno de pesquisa 2014-03). São Paulo: Grupo APOE.

Liñán, F., \& Chen, Y. (2009). Development and cross-cultural application of a specific instrument to measure entrepreneurial intentions. Entrepreneurship Theory and Practice, 33(3), 593-617. https://doi.org/10.1111/ j.1540-6520.2009.00318.x

Loiola, E., Gondim, S. M. G., Pereira, C. R., \& Ferreira, A. S. M. (2016). Planned behavior and entrepreneurial intention among undergraduate students: Analyzing predictors and mediators. Revista Psicologia Organizaçōes e Trabalho, 16(1), 22-35. https://doi. org/10.17652/rpot/2016.1.706

Martins, F. S., Santos, E., \& Silveira, A. (2019). Intenção empreendedora: categorização, classificação de construtos e proposiçáo de modelo. Brazilian Business Review, 16(1), 46-62. https://doi.org/10.15728/bbr.2019.16.1.4

Oliveira, M. B. de (2019). O papel da contabilidade para manutenção do equilíbrio do mercado de capitais: um estudo de caso de escândalos contábeis e seus impactos (Trabalho de Conclusão de Graduação, Faculdade de Administração e Ciências Contábeis, Universidade Federal do Rio de Janeiro. Rio de Janeiro, Brasil).

Paiva, L., Sousa, E., Lima, T., \& Silva, D. (2020). Comportamento planejado e crenças religiosas como antecedentes da intenção empreendedora: Um estudo com universitários. Revista de Administração Mackenzie, 21(2), 1-29.

Paul, J., \& Shrivatava, A. (2016). Do young managers in a developing country have stronger entrepreneurial intentions? Theory and debate. International Business 
Review, 25(6), 1197-1210. https://doi.org/10.1016/j. ibusrev.2016.03.003

Pico, L. M. S. (2019). El papel del contador en la proyección virtual. Revista CLIC, 3(1), 1-2.

Ramos, M. P. (2013). Métodos quantitativos e pesquisa em Ciências Sociais: Lógica e utilidade do uso da quantificação nas explicaçôes dos fenômenos sociais. Mediaçóes - Revista de Ciências Sociais, 18(1), 55-65. https://doi.org/10.5433/2176-6665.2013v18n1p55

Rizzato, S. de C. e C., \& Moran, M. C. (2013). Empreendedorismo e personalidade: $\mathrm{O}$ perfil em estudantes brasileiros. Revista Psicologia: Organizaçôes e Trabalho, 13(3), 279-292.

Rocha, E. L. de C., \& Freitas, A. A. F. (2014). Evaluation of teaching entrepreneurship among university students by means of an entrepreneur profile. Revista de Administração Contemporânea, 18(4), 465-486. https://doi. org/10.1590/1982-7849rac20141512

Schaefer, R., \& Minello, I. F. (2019). Entrepreneurial education: entrepreneurial mindset \& behavior in undergraduate students and professors. Revista de Negócios, 24(2), 61-90. https://doi.org/10.7867/19804431.2019v24n2p61-90

Silva, L. M. da, Krüger, C., Minello, I. F., \& Ghilardi, W. J. (2019). Empregado ou empresário? A intençâo empreendedora de alunos de graduação em Ciências Contábeis. Saber Humano: Revista Cientifica da Faculdade Antônio Meneghetti, 9(14), 77-109. https://doi. org/10.18815/sh.2019v9n14.355
Souza, R. dos S. (2015). Intenção empreendedora: Validação de modelo em universidades federais de Mato Grosso do Sul, Brasil (Tese de doutorado, Universidade Nove de Julho. São Paulo, Brasil).

Souza, R. dos S., Silveira, A., \& Nascimento, S. (2018). Ampliando a mensuração da intenção empreendedora. Revista de Administração FACES Journal, 17(2), 74-93. https://doi.org/10.21714/1984-6975FACES2018V17N2ART5319

Thompson, E. R. (2009). Individual entrepreneurial intent: Construct clarification and development of an internationally reliable metric. Entrepreneurship Theory and Practice, 33(3), 669-694. https://doi.org/10.1111/ j.1540-6520.2009.00321.x

Vergara, S. C. (2016). Projetos e Relatórios de Pesquisa em Administração. 16a Edição. Porto Alegre: Editora Atlas.

Wakefield, J., Tyler, J., Dyson, L. E., \& Frawley, J. K. (2019). Implications of student generated screencasts on final examination performance. Accounting \& Finance, 59(2), 1415-1446. https://doi.org/10.1111/ acfi. 12256

Fecha de recepción: 09 de noviembre de 2020 Fecha de aceptación: 09 de agosto de 2021 Correspondencia: cristiane.kruger@ufsm.br pedrohomrich@gmail.com claudia.michelin@ufsm.br 